\title{
CHALLENGES OF COMMUNICATION SYSTEM DURING EMERGENCY DISASTER RESPONSE IN MALAYSIA: A REVIEW
}

\author{
S. Azmani ${ }^{1}$, N. Juliana ${ }^{1, *}$, A. M. Idrose ${ }^{2}$, N. A. Amin ${ }^{3}$ and A. S. M. Saudi ${ }^{3}$ \\ ${ }^{1}$ Faculty of Medicine and Health Sciences, UniversitiSains Islam Malaysia, 55100 Kuala \\ Lumpur, Malaysia \\ ${ }^{2}$ Emergency and Trauma Department, Hospital Kuala Lumpur, 50586 Kuala Lumpur, \\ Malaysia \\ ${ }^{3}$ Institute of Medical Science Technology (MESTECH), Universiti Kuala Lumpur, 43000 \\ Kajang, Selangor, Malaysia
}

Published online: 05 October 2017

\begin{abstract}
The purpose of this review is to provide the overview of available systems and potential future systems for communication during disaster in Malaysia. Electronic searches in major subject loci databases such as MEDLINE (via PUBMED), Ovid, Science Direct, Scopus, IEEE Xplore digital library and Springer are used in conducting the reviews. The major challenge is to integrate between readily available communications systems at pre-disaster, during disaster and post-disaster. Therefore, this review will further provide information for the policy makers, responsible personnel as well as researchers on the vulnerability of the communication systems during disaster and the future direction of effective communication system in Malaysia.
\end{abstract}

Keywords: disaster; communication system;GIRN; effective communication system; emergency medicine.

\section{INTRODUCTION}

National Security Council (MNSC) Directive No. 20 (2012) delineates disaster as an incident

Author Correspondence, e-mail: njuliana@usim.edu.my

doi: http://dx.doi.org/10.4314/jfas.v9i4s.51 
which occur in a sudden manner and complex in its nature which causes losses of lives, damages to property or natural environment and perturb local activities [1]. Disaster in Malaysia can be divided into natural disasters, man-made disasters and subsequent disasters [2]. During the past decade, Malaysia faced numerous disasters including floods, landslides, transportation accidents, industrial accidents and collapse of buildings. These events caused physical and emotional distress among those who were involved either directly or indirectly [3].

Hence, in these kinds of situations, systematic communication system is essentially needed to ensure appropriate actions and proper managements can be carried out efficiently among the search and rescue teams [4,5]. During disaster, arrangement of emergency communications focuses on accurate information transfer between disaster sites to the responding base or hospitals and alternative communication method to be used when other means of communications such as the telephone and radio services fail to serve their purposes, either they are disabled or overwhelmed.Efficient emergency communication system during disaster will speed up relief and recovery operations, thus lessen the loss of life and properties [6].

Using available advanced communication technology to streamline emergency responses is a positive effort to integrate among the victims, community and organisations in charge of disaster management [7]. However, with the current system, there are still unsolved issues that include damage to communications infrastructure such as the power supply and network exacerbated difficulties in response and rescue during previous disasters of flood and landslides [8]. Disasters such as flood and tsunami are inevitable, but the sufferings can be minimized with proper communication system. Dissemination of timely, precise and comprehensible warnings to local populations involved and policy makers may reduce the losses and damages [9].

In this review paper we discuss the communication system during disaster in Malaysia and the loop holes to be improved. This review will focus on the development of communication system during disaster in Malaysia and the challenges to cope with crisis situations that arise due to natural or man-made disasters.

\section{SEARCH METHODS/DATABASES}

Electronic searches in major subject loci databases such as MEDLINE (via PUBMED), Ovid, Science Direct, Scopus, IEEE Xplore digital library and Springer are used in conducting the reviews. This review includes restrospective studies, cohort, cross-sectional and experimental studies. All the survey, simulation and modelling that relate to the communication system 
during disaster or disaster management are reviewed.

\section{RESULTS AND DISCUSSION}

\subsection{Disaster in Malaysia}

Geographically Malaysia is located outside the Pacific Rim of Fire, thus is protected from earthquakes and volcanoes. Before the millennia, Malaysia hadnever been struck by large-scale natural disasters [10]. However, in recent years, Malaysia was vulnerable to various natural hazards including large floods, tsunami, cyclonic storms and landslides that emerged from climatological changes [11].

Floods, landslides, droughts and the 2004-tsunami were significant natural disasters that alternately took place in Malaysia. Damaged of infrastructures and personal losses due to the disasters was estimated to reach billions of dollars [12-13]. In 2004, the first local tsunami that affected $200 \mathrm{~km}$ of Malaysia coastline from Perlis to Selangor caught Malaysia surprised and unprepared. The disaster resulted in 68 deaths, 6 declared missing, 91 hospitalized and 276 were treated as outpatient [14]. Ten years later, 2014 year end downpour and floods alone were estimated to cost the country 670 million USD of infrastructure losses along with mortality [15]. Besides that, local report of landslides events in Malaysia reported 56 landslides since the year of 1989 to 2009 [16-17]. Table 1 summarizes part of the natural disasters experienced by Malaysia. Malaysia also experienced man-made disasters from time to time. There were 18 local man-made disasters between the duration of 1968 to 2004 [10]. The disasters may have an acute impact to the nation or give rise to long-term disasters. There were few classifications of man-made disasters that lead to medical emergency response namely technological disaster, transportation accidents, and public failure (Table 1).

Previous disasters played an important role in the evolution and growth of the disaster management in Malaysia. Fig. 1 summarizes the current theoretical workflow of the rescue chain during disaster. Policy makers, legislation agencies and health care providers learned from the tormented history to increase level of disaster preparedness. Preparedness refers to steps taken before the occurrence of disaster in order to either avoid or reduce the effect of disaster [18]. Part of the preparations must include enhancing the effectiveness of emergency response by strengthening available strategic planning, operational procedures, tactical tiers, public training for disaster risks and responses and effective communication system [19-20]. 
Table 1. Natural and Man-Made disasters that occurred in Malaysia

\begin{tabular}{|c|c|c|c|c|}
\hline $\begin{array}{l}\text { Types of } \\
\text { Disaster }\end{array}$ & Area Affected & Year & $\begin{array}{l}\text { Number } \\
\text { of } \\
\text { Fatalities }\end{array}$ & Impact \\
\hline \multirow[t]{7}{*}{ Floods [21] } & Kuala Lumpur & 1971 & 32 & $\begin{array}{l}180,000 \text { people were affected } \\
\text { Set up of Kuala Lumpur flood } \\
\text { mitigation programme }\end{array}$ \\
\hline & Northeast & 1993 & 10 & 13,000 people were \\
\hline & Kinabatangan & 2000 & 2 & affected, 16 houses being \\
\hline & Kelantan + Terengganu & 2000 & 10 & swept away \\
\hline & East Malaysia & & & 20 villages affected, 4000 \\
\hline & East Malaysia & 2001 & 11 & people evacuated \\
\hline & & 2014 & 10 & $\begin{array}{l}\text { Thousands people evacuated } \\
200 \text { thousands evacuated }\end{array}$ \\
\hline \multirow[t]{5}{*}{$\begin{array}{l}\text { Landslide } \\
\text { [17] }\end{array}$} & $\begin{array}{c}\text { Kuala LipisGuaMusang } \\
\text { Road }\end{array}$ & 1993 & 1 & 15 casualties \\
\hline & Cameron Highlands & 1994 & 7 & \\
\hline & Genting Highland & 1995 & 20 & 22 casualties \\
\hline & $\begin{array}{l}\text { Mud-slide PosDipang } \\
\text { Bukit Antarabangsa }\end{array}$ & 1996 & 44 & \\
\hline & & 1999 & 1000 & \\
\hline $\begin{array}{l}\text { Tsunami } \\
{[22,14]}\end{array}$ & $\begin{array}{l}\text { Malaysia coastline } \\
\text { (Perlis to Selangor) }\end{array}$ & 2004 & 68 & 767 injuries and 6 missing \\
\hline Storm [23] & $\begin{array}{l}\text { Tropical storm Greg } \\
\text { West Coast, Sabah }\end{array}$ & 1996 & 230 & 4925 damaged houses \\
\hline \multirow[t]{4}{*}{ [24-25] } & $\begin{array}{l}\text { Enteroviral outbreak } \\
\text { Sibu Sarawak }\end{array}$ & 1997 & 25 & \\
\hline & SARS, Malaysia & 2003 & 2 & 3 cases recovered \\
\hline & & 2000 & 2 & 100 hospitalised, 901 nurseries \\
\hline & $\begin{array}{l}\text { Hand, foot and mouth, } \\
\text { Johor }\end{array}$ & & & closed \\
\hline
\end{tabular}

Technological Fire and explosion, $\quad 1991 \quad 23 \quad 103$ injuries recorded, factory 


\begin{tabular}{|c|c|c|c|c|}
\hline \multirow[t]{4}{*}{ disaster [26] } & bright sparkles & & & $\begin{array}{l}\text { and residential buildings were } \\
\text { damaged }\end{array}$ \\
\hline & $\begin{array}{c}\text { Fire and explosion } \\
\text { Choon Hong III Ship, }\end{array}$ & 1992 & 13 & $\begin{array}{c}\text { Loss of ship and damage of } \\
\text { jetty }\end{array}$ \\
\hline & Tiram Kimia, Klang & & & \\
\hline & Selangor & & & \\
\hline \multirow[t]{10}{*}{$\begin{array}{c}\text { Transportation } \\
\text { accidents }\end{array}$} & $\begin{array}{c}\text { Tourist bus accident, } \\
\text { Ravine, Genting }\end{array}$ & 1996 & 17 & \\
\hline & Highland, Pahang & & & \\
\hline & Merapoh Bus Tragedy & & 14 & \\
\hline & Bukit Gantang bus crash & 2003 & & \\
\hline & Cameron highlands bus & & 20 & \\
\hline & crash & 2007 & & \\
\hline & GentingSempah-Genting & & 27 & \\
\hline & Highland bus crash & 2010 & & \\
\hline & & & 37 & 16 casualties \\
\hline & & 2013 & & \\
\hline
\end{tabular}

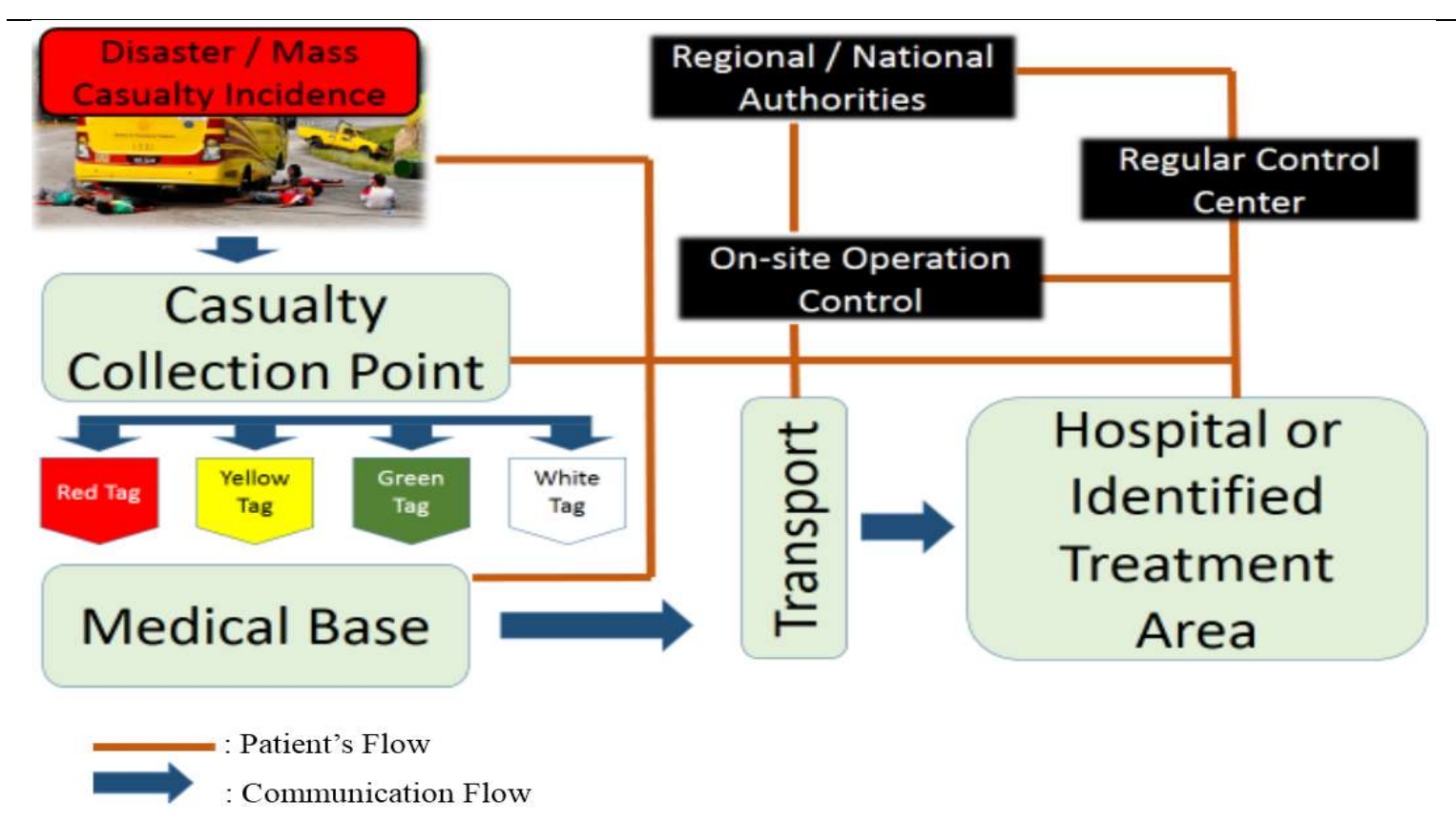

Fig.1.Theoretical workflow of the rescue chain

\subsection{Emergency Communication Services in Malaysia and Its Vulnerability}

The recent susceptibility for emergencies and disaster to affect Malaysia provides urgency for 
Malaysian government and policy makers to enhance and optimize the emergency communication system. Experts from multiple disciplines had propounded ideas of utilizing various types of communication systems as a mechanism to inform affected parties and react to adverse events [27].

\subsubsection{Universal Emergency Number}

In July 2007, Malaysian government has launched the 'One nation, one number' system of the universal emergency number ' 999 ' for all types of emergencies. The system was made to be public friendly and has proven to be very useful for early activation of the emergency medical services in cases of emergencies including disasters [28]. Nonetheless, since the launching of this number there was higher prevalence of prank calls as compared to actual emergency. The number may be centralized but the uniformity of emergency medical services communication system between different agencies is still inadequate. Each distinct agency relies on their own communication system of call-receiving and dispatching of response teams [29]. The incoordination leads to inappropriate transfer, overlapping in services and lapse of response. Up to date, the coordination was still done manually.

\subsubsection{Fixed, Mobile Networks and Internet-based Communication}

Landlines communication system has been used for decades during emergency and disaster situation. The system uses copper of fiber optic cables, which are vulnerable to damage when exposed to elements in case of flood and storm. The system that is non-portable and highly infrastructure-dependent is not a popular communication system to be relied as the main communication system during disaster [30].

Main difference during daily emergency situation and disaster is the massive nature of disaster. Therefore, in the event of disaster, communication through networks may leads to network congestion. Survey based on the 2014 flood in the East Coast of Malaysia showed that social media was the main resource of exchanging information among public with the flood victims [31]. Flood victims seem to gravitate towards using mobile messaging application to share information on the situation. Despite, the high prevalence of social media usage during the event, effective response for disaster relief was found to be relatively low [32]. Social media and up to date communication technologies maybe regarded as the fastest point of reference in times of crisis, but the vast information received without restriction via multiple databases exaggerate the difficulty of effective and accurate response to be provided for the victims [33-34]. Another study during the Great East Japan earthquake on 2011 in other hand showed that the use of mobile phones, laptops and landline phones usage were rated poor to moderate satisfactory level during disaster relief [35]. 
Another usage of the mobile networks will be receiving a real-time disaster information system from sensors placed at certain disaster susceptible sites. Study in Taiwan reported the system which include geographical disaster monitoring and alarm transfer via mobile networks is important to assist the prevention and early response during disaster situation. However, up to date, there is still no such integrated system from susceptible disaster area within Malaysia that directly link with the emergency system for early forecast of disaster [36].

Internet-based communication system such as 'Whats App' had been used effectively during the 2014 Gentingbus crash. During this event, the wifi services were functional from the incident site as well as all responding hospitals. The system proved to be extremely useful as communication was free, fast and clear. There is no 'lag time' when compared to walkie-talkie use. The informations exchanged were clear as all respondents could read the text. This is better than walkie-talkie conversations whereby only one person can talk at any one time. The quality of voice heard many times is not good and the information use is limited. More time is taken too as each person who talks needs to mention the person he wishes to speak, while every time needing to state when the conversation is over. It was also found that at the end of multiagency response, a 'log' can be produced and it could be stated who says what at which time [34]. This is extremely useful for post-mortem uses. The 'Whats App' and Twitter application also allows pictures, videos and audios to be transmitted from the site. Following this, during each mass casualty incidents, responders in hospitals in Malaysia utilize this mode of communication to complement the GIRN services. The only concern with the use of this mode of communication is the guarantee of security and confidentiality [33,21].

\subsubsection{Satellite-Based Communication}

Satellite-based communication is another alternative for communication in the event of disaster. Japan, United States of America and Russia are the countries that have utilised the system to disseminate emergency messages during previous disasters. Satellite-based communication is a robust system with the capability of transferring data and information to relevant geographical locations. Real-time disaster alert and also data transfer together with image transfer are the advantages of this system [37]. Furthermore, satellite communication system is a stand-alone system that is independent from terrestrial communications infrastructure. Therefore, the system is not susceptible to any damage of infrastructure during the disaster and telecommunication traffic congestion. The main dilemma is this system requires maintenance and the operation are costly for both users and service providers. It is important to note that in spite of the plausible capability of the system, signals from 
navigation satellites could only be received in outdoor environment. Another limitation is the vulnerability of the system to climatological phenomena such as fog and rain which are the common weather conditions in Malaysia [38].

\subsubsection{Radio Networks}

In Malaysia, there is an exclusive system Government Integrated Radio Network (GIRN) as an alternative for communication during disaster [39]. This radio network was made to have limitless network availability with high security encryption. The aims of this system are generally to provide a system that is resistant to any climatological factors with minimal infrastructure dependent. The radio network is a shared network between multiple agencies but each agency is able to maintain their independence and autonomy of their own communication system [40].Agencies involved in the networking are the national security, fire and rescue, health, ambulance frontier guards and other related agencies such as transportation companies, airports and delivery companies. GIRN is capable to enhance its coverage to areas outside its coverage by using Trunked Mode Operation (TMO) gateway, Direct Mode Operation (DMO) repeater. Up to date, there are few ambulance and agencies' official vehicles being equipped with RDU/CUBE to provide temporary network coverage at sites beyond GIRN network coverage. All these features are very useful at time of disaster to ensure continuous communication between local population effected and the rescue team. Nevertheless, GIRN is still incapable of transferring data in image forms [41]. Fig. 2 summarizes the components of GIRN.

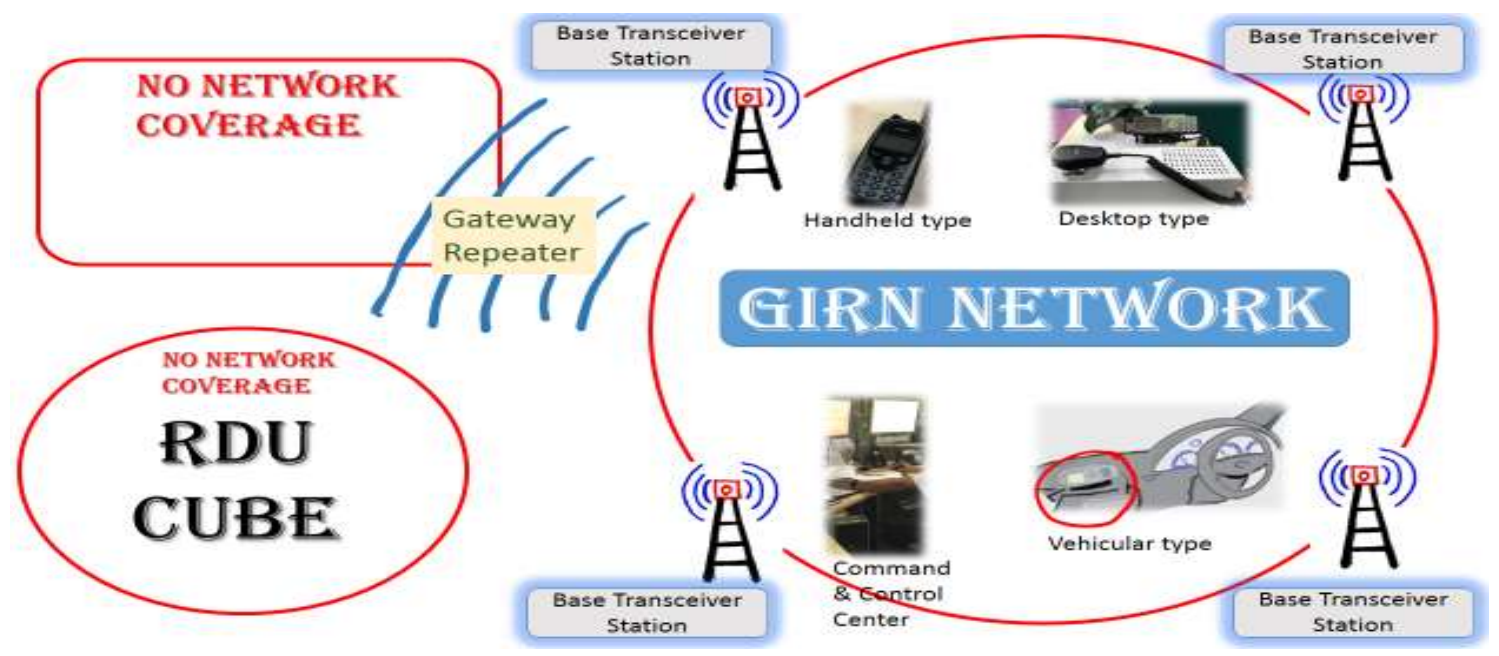

Fig.2. Component of GIRN in Malaysia

Malaysian Amateur Radio Emergency Service Society (MARES) is a local non-government Organisation (NGO), which provides emergency communication service during disaster. The organisation has been actively involved in providing disaster communication services to 
agencies such as Royal Malaysia Police, Red Crescent and Royal Malaysian Airforce [42]. Two distinct advantages of the amateur network are the independence of infrastructure used and most of the operators involved are skilled operators. Radio amateur network have proved to be very useful during disaster since the incidence of Highland Tower (1993), tsunami (2004), save and rescue operation for Piper 28 at GentingBidai (2005) and the list continues up to recent disasters that struck Malaysia [43]. Nonetheless, in order for amateur radio operators to be able to contribute in the event of disaster, local public officials must be conscious of the network capabilities and limitations.

\subsection{Ideal Communication System for Disaster Preparedness}

Previous literatures suggested prepositioning of relief supplies to areas that are disaster-prone in order to expedite distribution of supplies to victims once disaster struck. However, this type of disaster preparation requires high investment with uncertainty of the occurrence of disaster. Solid model of communication system in the event of disaster is the best solution for fast relief and accurate dissemination of resources to areas affected [44]. Therefore, few disaster models suggested tangible and intangible investments for disaster communication system. Tangible investments include improvement of available infrastructures such as communications equipment and information technology needed for disaster response together with emergency power plants. In other hand, intangible investments include training of staffs, hiring experts on communication system and educating vulnerable communities to recognize specific pre-disaster events and to respond appropriately [45]. Malaysia has a sturdy mechanism and framework in the disaster management and communication during disaster following the National Security Council Directive No. 20 [46,1]. The framework clearly lined the roles and responsibilities of each different agency and the communication flow in order to gain information and to communicate when disaster occurs. Hence, the information on the mechanism and framework must be made known to all staffs involved and also public especially the population at vulnerable areas with high risk of disaster occurrence.

Disaster communication system includes sending, receiving and retrieving accurate data ideally at pre, during and post disaster. Therefore, it is very important to have well-developed software preferably managed by an agency with strong management and commitment for crisis and disaster management [47]. Functional data distribution system is crucial at interface level to control who gets the information, at different time and at different places. In order to secure data inflow and outflow, data distribution system must be able to verify, control the quality and store the data. Thus, all important data can be further managed into thematic application such as natural disaster namely flood, landslides, forest fire and many more. All 
these data management system is an intelligent communication system that may enable later damage assessment, thematic hazards maps and risk prediction [48].

Part of the challenges that we learnt from previous disasters was the deployed ad hoc communication network might be susceptible to errors and security hazards [28]. During the 2015 flood which affected the northeast region of Malaysia, the emergency response network utilized was vulnerable to exaggeration of the actual event, thus creating more panic situation [49]. Faulty information being disseminated may temper with the routing of actual data messages in the network. The interruption may affect the reliability of emergency response networks, hence distracting emergency response efforts [50]. Recent work on web-based Community Emergency Management and Awareness System (CEMAS) in Malaysia is a joint effort between National Security Council of Malaysia and academic research to provide systematic communication with public regarding information on disaster. Sublime communication network should provide adequate security services for reliable and secure information exchange. Identity of the information source should be validated in order to determine the authentication of data received. Therefore, it is suggestible to incorporate strict security services in the framework of disaster communication system [51].

\section{CONCLUSION}

Based on the studies reviewed, it is important to determine the role of each communication systems in modulating the event of disaster. Most of the cross sectional and cohort studies indicated that advancement of various communication technologies offers opportunity for better disaster management hence reduced disaster-induced fatalities. However, serious consideration should focused on structuring the communication system during disaster with security encryption. Furthermore, special backup network that least infrastructure dependent and allows immediate communication between disaster relief agencies must always be readily operational. The limitation on the studies is that the integrated role of the readily available communication system during disaster does not elaborate robustly in mechanistic ways of the flow during disaster management [52].

Natural disaster is inevitable, however, minimizing duration of response time and bringing accurate resources during the response may reduce its severity. Therefore, prediction of the next disaster at pre-disaster state and risk stratification based on previous disasters need to be taken into account as the alternative way to aid in reducing the degree of damage. Part of the annual disaster that struck Malaysia was the northeast flood. Based on the forecast, pre-disaster communication system may assist in disseminating contingency plans lined by 
the government to vulnerable population with high risk. The limitations discussed in previous surveys described that public knowledge on disaster response and resources are still reserved. Therefore, future disaster communication system should include data that reflect the knowledge transferred to the community together with level of community awareness [53]. Finally, in this brief review, we conclude that the major challenge is to integrate between readily available communications systems at pre-disaster, during disaster and post-disaster. The integration may assist in organizing local communication systems in the event of disaster. Moreover, this brief review also highlights the importance and preeminence of the GIRN system during disaster. Nevertheless, the capabilities of the system should be utilized to the maximum. As the system is not subjected to network congestion and infrastructure damage, unlimited data may be received and disseminated during disaster [54]. Therefore, the future of this system may be improved by utilizing this system for image transfer such as image of onsite disaster overview, injuries, and crucial data [55]. Hence, there is a need to conduct robust multidisciplinary studies on effective communication system for disaster that include experts in emergency medicine, public health, information communication technology, engineering and last but not least the policy makers [56].

\section{ACKNOWLEDGEMENTS}

We would like to thank Prototype Development Research Grant Scheme (PRGS/1/2015SKK03/USIM/02/1) for providing the fund in development of communication system to be utilised during disaster.

\section{REFERENCES}

[1] Rahman B A. Issues of disaster management preparedness: A case study of directive 20 of National Security Council Malaysia. International Journal of Business and Social Science, 2012, 3(5).85-92

[2] Mohamed S I, Ahmadun F L. Disaster types in Malaysia: An overview. Disaster Prevention and Management: An International Journal, 2006, 15(2):286-298

[3] Bhushan B, Sathya K J. Emotional distress and posttraumatic stress in children surviving the 2004 tsunami. Journal of Loss and Trauma, 2007, 12(3):245-257

[4] Lettieri E, Masella C, Radaelli G. Disaster management: Findings from a systematic review. Disaster Prevention and Management, 2009, 18(2):117-136

[5] Okumura T, Suzuki K, Fukuda A, Kohama A, Takasu N, Ishimatsu S, Hinohara S. The Tokyo subway sarin attack: Disaster management, Part 1: Community emergency response. 
Academic Emergency Medicine, 1998, 5(6):613-617

[6] Bharosa N, Lee J, Janssen M. Challenges and obstacles in sharing and coordinating information during multi-agency disaster response: Propositions from field exercises. Information Systems Frontiers, 2010, 12(1):49-65

[7] McLennan B, Whittaker J, Handmer J. The changing landscape of disaster volunteering: Opportunities, responses and gaps in Australia. Natural Hazards, 2016, 84(3):2031-2048

[8] Manoj B S, Baker A H. Communication challenges in emergency response. Communications of the ACM, 2007, 50(3):51-53

[9] Acar A, Muraki Y. Twitter for crisis communication: Lessons learned from Japan's tsunami disaster. International Journal of Web Based Communities, 2011, 7(3):392-402

[10] Mohamed S I. Disaster types. Disaster Prevention and Management, 2007, 16(5):704-717

[11] Shaluf I M, Ahmadun F L, Mat S A. A review of disaster and crisis. Disaster Prevention and Management, 2003, 12(1):24-32

[12] Aini M S, Fakhru'l-Razi A, Daud M. Evolution of emergency management in Malaysia. Journal of Contingencies and Crisis Management, 2001, 9(1):46-53

[13] Said A M, Ahmadun F L, Kadir R A, Daud M. Inquiries into Malaysia's socio-technical disasters: Recommendations and lessons learnt. Disasters, 2009, 33(2):308-328

[14] Teh S Y, Koh H L, Liu P L, Ismail A I, Lee H L. Analytical and numerical simulation of tsunami mitigation by mangroves in Penang, Malaysia. Journal of Asian Earth Sciences, 2009, $36(1): 38-46$

[15] Tehrany M S, Pradhan B, Jebur M N. Flood susceptibility mapping using a novel ensemble weights-of-evidence and support vector machine models in GIS. Journal of Hydrology, 2014, 512:332-343

[16] Lee S, Pradhan B. Landslide hazard mapping at Selangor, Malaysia using frequency ratio and logistic regression models. Landslides, 2007, 4(1):33-41

[17] Pradhan B. Remote sensing and GIS-based landslide hazard analysis and cross-validation using multivariate logistic regression model on three test areas in Malaysia. Advances in Space Research, 2010, 45(10):1244-1256

[18] Jaeger P T, Shneiderman B, Fleischmann K R, Preece J, Qu Y, Wu P F. Community response grids: E-government, social networks, and effective emergency management. Telecommunications Policy, 2007, 31(10):592-604

[19] Kapucu N. Interagency communication networks during emergencies: Boundary spanners in multiagency coordination. The American Review of Public Administration, 2006, 
$36(2): 207-225$

[20] Tseng P T, Yen D C, Hung Y C, Wang N C. To explore managerial issues and their implications on e-Government deployment in the public sector: Lessons from Taiwan's Bureau of Foreign Trade. Government Information Quarterly, 2008, 25(4):734-756

[21] Aisha T S, Wok S, Manaf A M, Ismail R. Exploring the use of social media during the 2014 flood in Malaysia. Procedia-Social and Behavioral Sciences, 2015, 211:931-937

[22] Nah A M, Bunnell T. Ripples of hope: Acehnese refugees in post-Tsunami Malaysia. Singapore Journal of Tropical Geography, 2005, 26(2):249-256

[23] Komoo I, Aziz S, Sian L C. Incorporating the Hyogo Framework for Action into landslide disaster risk reduction in Malaysia. Bulletin of the Geological Society of Malaysia, 2011, 57:7-11

[24] Podin Y, Gias E L, Ong F, Leong Y W, Yee S F, Yusof M A, Perera D, Teo B, Wee T Y, Yao S C, Yao S K. Sentinel surveillance for human enterovirus 71 in Sarawak, Malaysia: Lessons from the first 7 years. BMC Public Health, 2006, 6(1):180-190

[25] Chua K B, Kasri A R. Hand foot and mouth disease due to enterovirus 71 in Malaysia. Virologica Sinica, 2011, 26(4):221-228

[26] Mohamed S I, Ahmadun F L. Disaster types in Malaysia: An overview. Disaster Prevention and Management, 2006, 15(2):286-298

[27] Salihu K Z, Ibrahim R, Khaidzir K A. The development of agent based modeling framework for simulating disaster response teamwork. International Journal of Management Excellence, 2013, 1(2):18-25

[28] Hisamuddin N N, Hamzah M S, Holliman C J. Prehospital emergency medical services in Malaysia. Journal of emergency Medicine, 2007, 32(4):415-421

[29] Ong M E, Cho J, Ma M H, Tanaka H, Nishiuchi T, Al Sakaf O, Abdul K S, Khunkhlai N, Atilla R, Lin C H, Shahidah N. Comparison of emergency medical services systems in the pan-Asian resuscitation outcomes study countries: Report from a literature review and survey. Emergency Medicine Australasia, 2013, 25(1):55-63

[30] Banipal K. Strategic approach to disaster management: Lessons learned from Hurricane Katrina. Disaster Prevention and Management, 2006, 15(3):484-494

[31] Ohto H. What we have learnt from past disasters, how do we prepare for future calamities? Transfusion and Apheresis Science, 2016, 55(2):173-176

[32] Utz S, Schultz F, Glocka S. Crisis communication online: How medium, crisis type and emotions affected public reactions in the Fukushima Daiichi nuclear disaster. Public Relations Review, 2013, 39(1):40-46 
[33] Carley K M, Malik M, Landwehr P M, Pfeffer J, Kowalchuck M. Crowd sourcing disaster management: The complex nature of Twitter usage in Padang Indonesia. Safety Science, 2016, 90:48-61

[34] Yates D, Paquette S. Emergency knowledge management and social media technologies: A case study of the 2010 Haitian earthquake. International Journal of Information Management, 2011, 31(1):6-13

[35] Kubo S I. Great East Japan earthquake. Rechtsmedizin, 2012, 22(1):12-16

[36] Wu C I, Kung H Y, Chen C H, Kuo L C. An intelligent slope disaster prediction and monitoring system based on WSN and ANP. Expert Systems with Applications, 2014, 41(10):4554-4562

[37] Suga T, Muto K, Yagi K, Onodera T, Nakada Y, Takano K. Thumbnail image size for image transmission system using satellite communication in disaster. Information (Japan), 2015, 18(3):1019-1027

[38] Al-Amin A Q, Rasiah R, Chenayah S. Prioritizing climate change mitigation: An assessment using Malaysia to reduce carbon emissions in future. Environmental Science and Policy, 2015, 50:24-33

[39] Othman S H, Beydoun G, Sugumaran V. Development and validation of a Disaster Management Metamodel (DMM). Information Processing and Management, 2014, 50(2):235-271

[40] Badpa A, Yavar B, Shakiba M, Singh M J. Effects of knowledge management system in disaster management through RFID technology realization. Procedia Technology, 2013, $11: 785-793$

[41] Uddin MN, Rashid MM, Nithe NA. Comparative study of integrated transceiver for real time monitoring in rescue operation. Einstein International Journal Organization, 2016, $1(1): 23-30$

[42] Martin N, Rice J. Emergency communications and warning systems: Determining critical capacities in the Australian context. Disaster Prevention and Management, 2012, 21(5):529-540

[43] Jusoff K. Search and rescue (SAR) operations for the missing Bell 206 Long Ranger helicopter in Sarawak, Malaysia using near real-time airborne hyperspectral imaging system. Disaster Prevention and Management, 2008, 17(1):94-103

[44] Cheema A R, Mehmood A, Imran M. Learning from the past: Analysis of disaster management structures, policies and institutions in Pakistan. Disaster Prevention and Management, 2016, 25(4):449-463 
[45] Alam A S, Reza M I, Begum H, Er A C, Pereira J J. Promoting community for disaster risk reduction. Advanced Science Letters, 2015, 21(6):1700-1703

[46] Mohamed S I, Ahamadun F L. An overview on the offshore emergency response planning in Malaysia. Disaster Prevention and Management, 2008, 17(1):83-93

[47] Mansourian A, Rajabifard A, Zoej M V, Williamson I. Using SDI and web-based system to facilitate disaster management. Computers and Geosciences, 2006, 32(3):303-315

[48] Mat S A, Ahmadun F L, Rodzi M A, Abas F. Community preparedness for tsunami disaster: A case study. Disaster Prevention and Management, 2011, 20(3):266-280

[49] Chong Z X. Experience of a medical student: Volunteering in the emergency department during massive flood in Kelantan, Malaysia. International Journal of Medical Students, 2015, 3(3):163-164

[50] Tahir W, Jani J, Endut I R, Mukri M, Kordi N E, Ali N E. Flood Disaster Management in Malaysia: Standard Operating Procedures (SOPs) Review. In International Symposium on Flood Research and Management, 2016, pp. 31-43

[51] Ludin S M, Ludin S M, Arbon P A, Arbon P A. Improving community disaster resilience through scorecard self-testing. Disaster Prevention and Management, 2017, 26(1):13-27

[52] Billa L, Shattri M, Rodzi M A, Halim G A. Comprehensive planning and the role of SDSS in flood disaster management in Malaysia. Disaster Prevention and Management, 2006, 15(2):233-240

[53] Hossain L, Kuti M. Disaster response preparedness coordination through social networks. Disasters, 2010, 34(3):755-786

[54] Osman N N. Disaster management: Emergency nursing and medical personnel's knowledge, attitude and practices of the East Coast region hospitals of Malaysia. Australasian Emergency Nursing Journal, 2016, 19(4):203-209

[55] Yazid A S, Tengku T F, Abdullah A A, Daud W N, Salleh F, Husin M R. Flood risk mitigation: Pressing issues and challenges. International Review of Management and Marketing, 2017, 7(1):157-163

[56] Khairilmizal S, Hussin M F, Mohd Y A I, Hussain A R, Husna K A, Jusoh M H, Sulaiman A A, Saadun J, Kasri M H. Policy on disaster management in Malaysia: The need of supporting governance. Advanced Science Letters, 2016, 22(12):4213-4215

\section{How to cite this article:}

Azmani S, Juliana N, Idrose A M, Amin N A, Saudi A S M. Challenges of communication system during emergency disaster response in malaysia: a review. J. Fundam. Appl. Sci., 2017, 9(4S), 890-904. 